\title{
Benefícios do Programa PECS-Adaptado para um Aluno com Paralisia Cerebral $^{1}$ Benefits of PECS-Adapted Program for a Student With CEREBral PaLsy
}

\author{
Fabiana Lacerda EVARISTO \\ Maria Amélia ALMEIDA ${ }^{3}$
}

\begin{abstract}
RESUMO: a comunicação humana constitui uma troca de sentimentos e necessidades entre duas ou mais pessoas, seja realizada pela linguagem oral, gestual, gráfica e/ou escrita. Com isso, este estudo teve como objetivo verificar os efeitos da implementaçáo do Sistema de Comunicação por intercâmbio de figuras associada a metodologia do Currículo Funcional (PECS-Adaptado) em um aluno com paralisia cerebral. A pesquisa foi realizada nas dependências de uma escola de educaçáo especial, em uma cidade de pequeno porte localizada no interior do estado de São Paulo. Participaram do estudo um aluno com paralisia cerebral e sem a fala oral, sua professora e seus pais. Os pais do aluno e a professora foram orientados para a utilizaçáo do sistema em casa e na escola, respectivamente, instrumentalizando assim interlocutores mais imediatos. A coleta dos dados durou aproximadamente sete meses. Durante a pesquisa, observou-se que o participante com paralisia cerebral aumentou suas habilidades comunicativas, de acordo com as suas necessidades e a professora e os pais compreenderam a importância do uso do sistema de comunicaçáo alternativa para o processo de ensino e aprendizagem.
\end{abstract}

PALAVRAS-CHAVE: Educação Especial. Comunicação Alternativa. Paralisia Cerebral.

\begin{abstract}
Human communication is an exchange of feelings and needs between two or more people, either carried out by oral, sign, graphic and/or written languages. Therefore, this study aimed to verify the effects of the implementation of the Picture Exchange Communication System. (PECS-adapted) for a student with cerebral palsy. The research was carried out in a special education school, in a small town in the state of São Paulo, Brazil. One non-speaking student with cerebral palsy participated in the research, his teacher and his parents. The parents and the teacher were guided in using the system at home and at school, and this instrumentalizing the most immediate partners. Data collection lasted about seven months. During the research, it was observed that the participant increased his communication skills, according to his needs, and the teacher and the parents understood the importance of using the alternative communication system for teaching and learning.
\end{abstract}

KEYWORDS: Special Education. Alternative Communication. Cerebral Palsy.

\section{INTRODUÇÁo}

A comunicação é vital para o desenvolvimento cognitivo, social e intelectual, assim pessoas com alteraçóes na qualidade e funcionalidade da mesma, podem sofrer grave impacto na qualidade de vida, necessitando, de um programa individual de reabilitação direcionada à orientação e instrumentalização do usuário e família (DUTRA; FAGUNDES; SCHIMER, 2007).

A paralisia cerebral ocorre no início da infância e é definida como uma desordem cerebral durante o desenvolvimento fetal ou por conta de uma lesão cerebral após o parto. Caracteriza por uma permanente condição que afeta, mas não invariavelmente, o tônus muscular, postura e movimento (BADAWI et al.,1998; MILLER, 2002).

\footnotetext{
${ }^{1}$ http://dx.doi.org/10.1590/S1413-65382216000400006

${ }^{2}$ Mestre em Educação Especial, Programa de Pós-graduação em Educação Especial, Centro de Educação e Ciências Humanas da Universidade Federal de São Carlos. São Carlos, SP, Brasil. fabi_lacerda15@hotmail.com

${ }^{3}$ Docente do Programa de Pós-graduação em Educação Especial, Centro de Educação e Ciências Humanas da Universidade Federal de São Carlos. São Carlos, SP, Brasil. ameliama@terra.com.br
} 
Para avaliação do desempenho das atividades funcionais de pessoas com paralisia cerebral pode-se usar a Classificação Internacional de Funcionalidade, Incapacidade e Saúde (CIF). A adoção e a classificação por profissionais da área da saúde tem grande importância ao descrever a funcionalidade e a incapacidade da pessoa, auxiliando os profissionais em seus procedimento de avaliação e intervenção, e também pode proporcionar uma linguagem padronizada (OMS, 2008).

A pessoa com paralisia cerebral pode apresentar dificuldades específicas segundo Brasil (2006, p. 20):

[...] No desempenho motor, ao andar, ao usar as mãos para comer, ao escrever, ao se equilibrar, ao falar, ao olhar ou qualquer outra atividade que exija controle do corpo e coordenação motora adequada, assim como comprometimentos das funçôes neurovegetativas como na sucção, mastigação e deglutição

Devido a essas limitações e incapacidades, a criança com paralisia cerebral poderá ter um atraso significativo no seu desenvolvimento motor, sensorial, perceptivo-cognitivo e na maneira de produzir linguagem expressiva, seja ela de forma oral ou escrita, desfrutando de oportunidades restritas (MANZINI, 2013).

O prognóstico da pessoas com paralisia cerebral depende do conhecimento, por parte do médico, de que não só a pessoa com deficiência necessita de atenção, mas também a família, sendo preciso ouvi-la e orientá-la. $\mathrm{O}$ atendimento focado na relação entre os pais e o filho, familiares, escola e comunidade é uma forma primordial de se atuar de maneira completa nos casos de paralisia cerebral, assim como no caso de outros tipos de deficiência (ROTTA, 2002).

Entre as diferentes causas, a linguagem das pessoas com paralisia cerebral é considerada um fator importante a ser estudado, visto que quando a fala oral é prejudicada, necessita de meios alternativos para se comunicar. As habilidades comunicativas de alunos com deficiência sem oralidade têm sido objeto de estudos pelos pesquisadores, que estão preocupados em garantir que estas pessoas possam demonstrar suas reais potencialidades em diferentes contextos, principalmente com interlocutores falantes (DELIBERATO; SAMESHIMA, 2007).

Tabith (1989) mencionou que são variados os comprometimentos existentes na comunicação das pessoas com paralisia cerebral, desde distúrbios articulatórios leves até retardos graves na aquisição ou ausência da fala, afirmando que $70 \%$ deles apresentam problemas relacionados com a comunicação. Destaca ainda, que as crianças com paralisia cerebral comunicam-se da maneira que lhes é possível, estruturando seu pensamento por meio de relaçóes que se estabelecem com duas experiências: muitas delas verbalizam; outras apresentam sérias alteraçóes da produção dos sons, não conseguindo transmitir suas vivências por meio de um código linguístico.

No campo Educacional, quando se enfoca o processo de ensino-aprendizagem de alunos com Paralisia Cerebral sem fala "funcional" (CHUN; MOREIRA, 1997) salienta-se a necessidade de meios alternativos de comunicação. Pelosi (2010) enfatiza que a recomendação e incentivo desses meios alternativos devem ser seguidos, caso se pretenda, de fato, oferecer oportunidades educativas à essa população. Do contrário, o processo torna-se inviável porque cria obstáculos na interação com esses alunos (CARNEVALE et al., 2013.) 
Para todas as pessoas com paralisia cerebral que têm expressão oral e escrita limitada, impossibilitados de realizá-las na idade habitual, é indicado o uso de um sistema de Comunicação Alternativa (CA), podendo ser utilizados como auxiliares primários ou suplementares, possibilitando à pessoa com deficiência a expressão da linguagem, superando os obstáculos da disfunção e tendo assim, acesso à comunicação (MIRANDA; GOMES, 2004).

Segundo a American Speech and Hearing Association - ASHA (1991), a Comunicação Alternativa é uma área de prática clínica de pesquisa e educacional para profissionais da área que visam compensar e facilitar, temporária, ou permanentemente, padrões de prejuízo e inabilidade de pessoas com severas desordens expressivas e/ou descobertas na compreensão de linguagem.

A Comunicação Alternativa apresenta várias técnicas e métodos que complementam ou substituem a linguagem oral comprometida ou ausente por meio do uso de recursos gráficos visuais e/ou gestuais. Dentre esses recursos encontramos símbolos produzidos pelo próprio corpo, envolvendo desde gestos simples até um complexo sistema de sinais manuais que compóe a língua de sinais. Como também encontramos formas de comunicação compostas de expressões linguísticas na forma física e fora do corpo do usuário, como objetos em miniatura, pranchas temáticas, sistemas de comunicação computadorizados, dentre outros (DELIBERATO; MANZINI; GUARDA, 2004).

Nesse contexto, é possível utilizar três diferentes tipos de sistemas de comunicação: os não apoiados, ou seja, que não envolvem qualquer tipo de recurso material, sendo usado apenas o próprio corpo como instrumento de comunicação; os sistemas apoiados de baixa tecnologia, recursos confeccionados de maneira artesanal, como por exemplo, pranchas de comunicaçáo; sistemas apoiados de alta tecnologia, tais como os sistemas computadorizados (NUNES, 2009).

O Picture Communication Symbols - PCS, sistema gráfico de comunicação, contém mais de 11.000 Símbolos de Comunicação Pictórica (PCS), ou seja, figuras de comunicação icônicas acompanhadas do vocábulo escrito que expressam uma grande variedade de palavras em situaçóes de atividades de vida diária e prática. Os símbolos PCS foram criados no início dos anos 80 pela fonoaudióloga americana Roxanna Mayer Johnson (JOHNSON, 2005).

Bondy e Frost (1994) utilizam o programa PECS (The Picture Exchange Communication System) desde 1990, caracterizando o programa por ser um sistema de comunicação por troca de figuras que permite às pessoas adquirirem habilidades de comunicação no contexto social. Os símbolos gráficos utilizados durante os procedimentos do PECS pertencem ao PCS e representam pessoas, substantivos, verbos, atributos (adjetivos e advérbios), conjunçôes, preposições, números, letras.

Walter (2000) descreveu uma pesquisa mostrando as adaptaçôes do PECS (BONDY; FROST, 1994) ao Currículo Funcional Natural (LEBLANC, 1991), por meio da redução dos números de fases e acrescentou algumas alteraçóes, como o uso da pochette como álbum de comunicação. $\mathrm{O}$ estudo teve resultados positivos aos padrôes de comunicação como: aquisição de algumas palavras e gestos; espontaneidade para solicitar o item desejado nas diferentes situ- 
açóes de vida diária e prática. A pesquisa concluiu a necessidade de continuar as adaptaçôes do PECS ao Currículo Funcional Natural.

Piza (2002) realizou uma pesquisa na qual aplicou as fases do PECS-Adaptado com três alunos que apresentavam paralisia cerebral severa. A pesquisadora utiliuzou o delineamento de linha de base múltipla entre participantes e verificou o desempenho dos participantes em cada sessão, o tipo de ajuda e o vocabulário emitido em cada sessão. As adaptaçóes realizadas no sistema PECS, no que diz respeito as necessidades físicas dos participantes com paralisia cerebral, auxiliou-os a a se comunicarem em situaçóes variadas com seus interlocutores, confirmando o estudo realizado por realizado por Walter (2000).

Outro estudo envolvendo pessoas com paralisia cerebral foi realizado por Almeida, Piza e Lamônica (2005), que também tinha como objetivo avaliar a eficácia do programa PECS e Picture Communication Symbols (PCS) na comunicação de uma criança com paralisia cerebral. Foi utilizado o delineamento $\mathrm{AB}$ e verificado o número de trocas com êxito e sem êxito. O participante foi capaz de passar por todas as fases do PECS-Adaptado e usar a prancha de comunicação nas atividades escolares. O PECS-Adaptado mostrou-se eficaz em melhorar a capacidade de comunicação do participante.

O PECS-Adaptado (WALTER, 2000) pode ser usado no contexto escolar, em casa e por profissionais especializados e deve cumprir todas as fases de treinamento descritas no programa, e o aluno deverá cumprir os objetivos finais de cada fase para passar à fase seguinte. $\mathrm{O}$ PECS-Adaptado conta com cinco fases de treinamento.

O PECS apesar de ter sido criado para pessoas com transtorno do espectro do autismo tem sido bem sucedido com outras deficiências que possuem graus de comunicação, dificuldades cognitivas e físicas variadas (BONDY; FROST, 1994).

Frente à necessidade de sistematizar as habilidades comunicativas apresentadas por alunos com deficiência, a escola se torna um ambiente importante para proporcionar o suporte linguístico às linguagens alternativas (TETZCHNER, 2009). A capacitação do professor se torna necessária ao ensino das habilidades comunicativas para o aluno com desordens na comunicação oral e/ou escrita e dessa forma ele possa ser compreendido e tenha oportunidade de expressar seus pensamentos e desejos com diferentes interlocutores (SILVA et al., 2013).

Este artigo teve como objetivo verificar os efeitos da implementação do Sistema de Comunicação por intercâmbio de figuras associada a metodologia do Currículo Funcional (PECS-Adaptado) por meio de uma prancha de comunicação alternativa em um aluno com paralisia cerebral e sem a fala oral.

\section{Método}

\subsection{Aspectos Éticos}

A presente pesquisa teve parecer favorável do Comitê de Ética em Pesquisa com Seres humanos, nos termos da resulução 196/96 e aprovação n409.523/2013. 


\subsection{Participantes}

Participaram quatro pessoas, sendo:

- Um aluno com paralisia cerebral, 28 anos de idade, frequenta escola de educação especial, apresenta tetraplegia espástica, necessitando usar cadeira de rodas e mesa adaptada para a execução de algumas atividades.

- O pai e a mãe desse aluno. Forneceram dados referentes a rotina do aluno em casa, da comunicação em casa e foram interlocutores imediatos.

- A professora dessa sala de aula, com o intuito de colaborar fornecendo dados gerais sobre a rotina e os alunos, como também foi interlocutora dos procedimentos de ensino.

\subsection{LOCAL}

A coleta dos dados foi realizada nas dependências da instituição filantrópica de Educação Especial em uma cidade de pequeno porte no interior do Estado de São Paulo.

\subsection{Materiais E EQUiPAMENTOS}

Para o desenvolvimento da pesquisa foram utilizados os seguintes materiais: folhas de sulfite A4; lápis preto; papel cartão de diferentes cortes (cartôes de comunicação); figuras diversas (símbolos gráficos - PCS e Boardmaker); cola quente; cola transparente; tesoura; pasta do tipo fichário; papel contact, para encapar as figuras.

Os equipamentos utlizados foram: uma câmera fotográfica e filmadora; uma impressora com tinta colorida e preta; e um notebook com entrada para CD/DVD.

\subsection{INSTRUMENTOS}

Foram utilizados como instrumentos:

- Roteiro de entrevista semiestruturada para a professora: teve como objetivo coletar dados de caracterização da professora: nome, idade, formação, local onde se formou, área especializada, local onde trabalha e há quanto tempo atua. Em segundo lugar, verificar o envolvimento que a professora apresentava sobre a CA. Por fim, obteve dados sobre como é a rotina e quais são as atividades desenvolvidas com os alunos.

- Roteiro de entrevista semi-estruturada inicial: foi composto por três perguntas de caracterização do respondente; e onze perguntas referentes ao perfil comunicativo do aluno em casa e as necessidades dos familiares. Este instrumento foi aplicado juntamente com a lista de interesses do aluno

- Roteiro de entrevista pós-intervençáo para os pais do aluno: foi composto por onze perguntas sobre a implementação da prancha de comunicação alternativa com o seu filho, após as intervençôes com as fases do PECS-Adaptado. Teve como objetivo obter dados relativos a comunicação do aluno da pesquisa, e principalmente saber se houve mudança nos procedimentos ensinados pela pesquisadora e professora. 
- Lista de interesses do aluno: foi composto por coisas preferidas para comer; coisas preferidas para beber; atividades preferidas (assistir televisão, sentar em alguma cadeira, etc.); brinquedos preferidos ou objetos que se interessa; jogos e brincadeiras preferidas (esconder, cócegas, músicas, etc.); lugares que gosta de visitar (lojas, parques, parentes, etc.) e pessoas que conhece e costuma ficar (empregada, avós, parentes, amigos, etc.).

- Protocolos de registros das fases do PECS-Adaptado: retirados do trabalho de Walter (2000) teve como objetivo descrever minuciosamente as filmagens de linha de base, intervenção e follow up. Esses protocolos apresentam informações básicas para as cinco fases do treinamento do PECS-Adaptado, sendo fase: 1, 2, 3a, 3b, 4 e 5.

- $\quad$ Protocolo de registros do diário de campo: O protocolo de registro do diário de campo das visitas na residência dos participantes e escola que frequentam teve como finalidade possibilitar uma análise qualitativa da rotina de trabalho com as crianças; e das intervenções e orientaçóes que foram realizadas.

\subsection{Procedimentos de INTERVENÇÁo}

Foi utilizado o Sistema de Comunicação por intercâmbio de figuras associada a metodologia do Currículo Funcional (PECS-Adaptado), associado às figuras do Boardmaker, por apresentar figuras de fácil compreensão. Essas figuras expressam uma variedade de palavras e situações de atividades de vida diária prática.

A seleção das figuras e escolha do vocabulário funcional foi feita com a seleção de um sistema adaptado e de baixa tecnologia. Consistia em figuras impressas em papel cartão. Essas figuras foram colocadas na prancha de comunicação alternativa sobre tiras de velcro, para que o aluno pudesse retira-las ao fazer algum pedido. Quando não fosse possível, o aluno apontava ou olhava para a figura, porém respeitávamos o tempo dele e a escolha de como desejava fazer.

A prancha de comunicação foi confeccionada em madeira, com duas tiras de velcro colado. Essa prancha tinha adaptação para encaixar na cadeira. Também foi confeccionada uma prancha de madeira inclinada, na qual facilitava o aluno alcançar a figura.

Além da prancha, tambéem foi confeccionada a pasta de comunicação. A pasta apresentava 34 folhas, fixando com tira de velcro seis figuras em cada folha, totalizando 200 figuras de comunicação confeccionadas. A capa da pasta apresentava a foto do participante com a seguinte frase: "quero me comunicar com você".
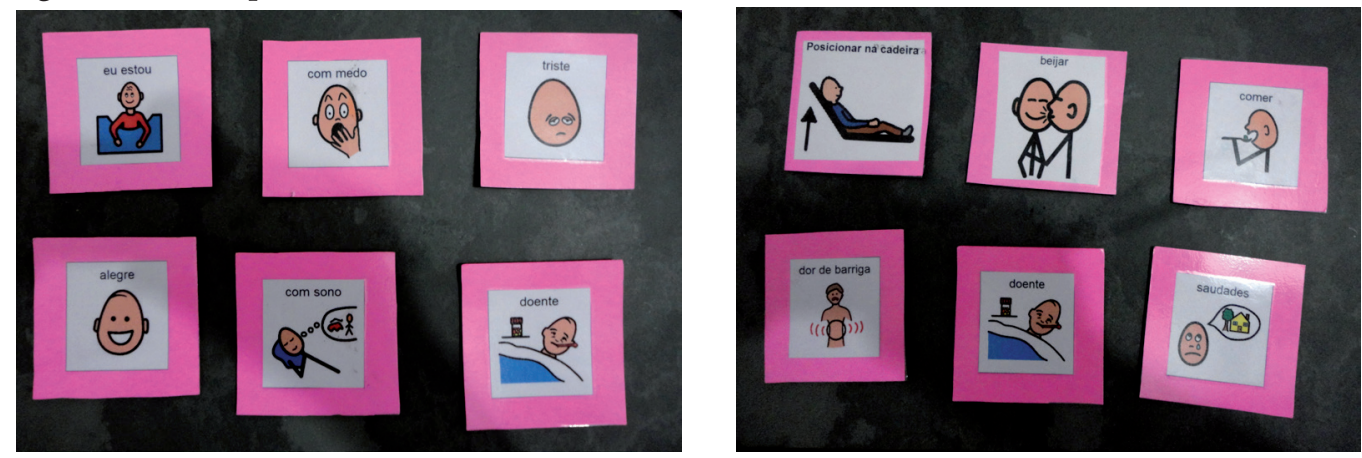

Figura 1 - Algumas figuras impressas em papel cartão

Fonte: elaboração própria. 
A coleta de dados iniciou-se com observaçôes do aluno, após iniciou-se a linha de base com as fases do PECS - Adaptado. As atividades referente as observaçóes e linha de base iniciaram-se no primeiro semestre de 2013, durando aproximadamente quatro meses.

O participante atendia as solicitações, se comunicava com o olhar e/ou pegava-as e apresentava função comunicativa. Foram realizadas 14 sessões de linha base, a partir da estabilidade comportamental em três sessóes consecutivas foi iniciada as fases de intervenção. No segundo semestre de 2013, iniciou-se as intervençóes e o follow up também de acordo com as fases do PECS-Adaptado, totalizando 21 sessões de intervenção, com finalização em dezembro de 2013.

A comunicação do participante aluno antes da implementação do programa ocorria por meio de gestos, corporal e expressão facial. Com isso, a comunicação muitas vezes era incompreensível. A introdução do PECS-Adaptado, seguindo a rotina diária do aluno, foi uma forma de estimular a comunicação eficaz por meio da troca de figuras com outros parceiros, afim de compreenderem o que o participante aluno pretendia comunicar.

A fase 1 consistia no treinamento da troca de figuras entre o aluno e a professora, correspondendo a um pedido de algo muito desejado. $\mathrm{O}$ aluno fazia pedido daquilo que desejava entregando a figura para a professora, e com isso recebia o desejo.

A fase 2 consistiu para aumentar a espontaneidade do aluno, ele apontou a figura da tábua ou do álbum de comunicaçáo, chamando uma pessoa através de gestos ou sons para realizar o pedido através da troca de figuras. Portanto, a a professora afastou-se do aluno e da prancha de comunicação e orientou que o aluno deveria chamar a professora caso quisesse realizar algum pedido e, quando esta se aproximasse de sua cadeira, deveria realizar a troca entregando a figura.

A fase 3a foi para o aluno discriminar entre várias figuras e apontar a figura da tábua ou álbum de comunicação para realizar o pedido através da troca de figuras. Neste caso a professora falava o nome da figura na qual o aluno deveria pegar, observando a sua facilidade para discriminar figuras.

$\mathrm{Na}$ fase $3 \mathrm{~b}$ o treinador diminuiu o tamanho das figuras de $8 \mathrm{~cm}$ para $4 \mathrm{~cm}$ e o aluno discriminou entre várias figuras. $\mathrm{O}$ procedimento era o mesmo da fase $3 \mathrm{a}$, porém as figuras foram diminuídas de tamanho e foram acrescentadas novas opçóes na prancha de comunicação alternativa.

A fase 4 teve como objetivo formar frases com "eu quero" e "eu estou". Como por exemplo, "eu quero água”. Ficavam dispostas na prancha a figura "eu quero" ou "eu estou”, como também estavam dispostas figuras referentes ao desejo do aluno. Ele entregava, apontava ou movimentava a cabeça para a figura desejada e a professora entregava o desejo correspondente.

Ao dar inicio a fase 5, o aluno foi orientado em relação a forma como deveria realizar a troca, seria aplicado o mesmo procedimento da fase 4, mas com a inserção de mais figuras e conceitos. Nessa fase o objetivo foi aumentar o vocabulário do aluno, utilizando o maior número possível de figuras, com conceitos de tamanho, cor, forma, localização, etc., em todas as situações de vida.

O follow up, foi a avaliação da continuidade das fases do PECs-Adaptado, com uma tentativa de cada fase, para observar se as aprendizagens ensinadas foram mantidas. $\mathrm{O}$ objetivo 
foi observar se os comportamentos do aluno foram mantidos e realizar uma manutenção dos mesmos e consequentemente observar as respostas das habilidades comunicativas do aluno.

\subsection{Procedimentos de coleta dos dados}

Como procedimentos para coleta dos dados foi entregue aos pais dos alunos da sala de aula, à professora e à instituição, o termo de consentimento livre e esclarecido para a participação na pesquisa. Posteriormente foi realizada a entrevista com a professora que baseou-se no seu envolvimento com a área de comunicação alternativa.

Foram iniciadas as visitas na instituição, com a realização das observaçóes. Estas foram para relatar quais atividades o participante realizava na escola, de acordo com a sua rotina diária na escola. O participante foi submetido à avaliaçóes iniciais, correspondente às sessóes da linha de base e, em seguida, foi iniciada a intervenção com o treinamento das fases do PECSAdaptado (WALTER, 2000).

A coleta, portanto, ocorreu no período em que o aluno participante estava na escola. As sessóes de intervenção ocorreram durante as atividades: na hora do jantar e em sala de aula, no período vespertino.

Para cada fase do PECS-Adaptado, foi elaborada uma folha de registros contendo a sequência de passos a serem completados pelo aluno, podendo passar para o passo seguinte ou retroceder, se for necessário. Esses protocolos de registros foram adaptaçóes do PECS - Sistema de Comunicação por Intercâmbio de Figuras (BONDY; FROST, 1994), realizada pela Walter (2000), para cada fase de intervenção.

Em cada sessão, foi descrito a atividade selecionada para o treino e as figuras que foram utilizadas, de acordo com a lista de interesses previamente preenchida pelos pais e pela professora, na seleção do vocabulário. Os dados das visitas e intervençóes foram anotados no diário de campo e no protocolo de registros das fases do PECS- Adaptado.

Após a finalização da fase $3 \mathrm{~b}$, os pais foram convidados para acompanhar os procedimentos de ensino e serem capacitados como interlocutores imediatos, também foi realizada uma entrevista com os pais do aluno, a fim de saber a opiniâo deles sobre a melhora ou não das habilidades comunicativas do seu filho.

Os dados foram coletados no decorrer de aproximadamente dez meses durante o ano de 2013, mostrando assim, o desempenho do aluno em comunicar seus desejos, sentimentos e necessidades por meio da comunicaçáo alternativa, utilizando o treinamento das fases do PECS-Adaptado (WALTER, 2000).

\subsection{Procedimento de ANÁlise doS dados}

Os dados de registro de observação do participante aluno foram organizados por meio dos diários de campo. $\mathrm{O}$ acompanhamento diário do desempenho do participante foi anotado nos protocolos de registro das fases do PECS-Adaptado.

As atividades videogravadas, foram analisadas e interpretadas identificando as características de comunicação do participante, de acordo com o objetivo proposto de cada fase. 
Foi utilizado o Delineamento de Sujeito Único AB, que tem o sujeito como seu próprio controle e por ser uma forma simples de se estabelecer relação entre a variável dependente e a variável independente em fenômenos pouco explorados, sendo utilizados em projetos de intervenção (GAST, 2010; GAST; LEFORD, 2014).

Nesse estudo, a variável independente é a aplicação do programa pela pesquisadora a qual, tem como variável dependente direta o comportamento comunicativo do participante com paralisia cerebral (GAST, 2010; GAST, LEFORD, 2014).

O delineamento tem duas fases: "A" se refere à fase de linha de base e "B" se refere à fase de intervenção. Quando a linha de base, fase "A", foi estabelecida a intervenção foi introduzida e a fase " $\mathrm{B}$ " é iniciada. Os dados da intervenção coletados foram passados para o gráfico. A intervenção, por fim só pode ser introduzida depois de ser observada a estabilidade comportamental (GAST, 2010).

\section{Resultados E Discussófes}

A coleta de dados baseou-se em observaçóes do participante aluno, sessóes de linha de base e intervenção por meio das fases do PECS - Adaptado.

A adaptação do PECS foi baseada na necessidade de se associar o recurso de comunicação alternativa voltado ao ensino funcional, fazendo com que o participante pudesse estabelecer um canal comum de comunicação que fosse mais eficaz e mais rápido, do que a utilização de gestos padronizados e, ao mesmo tempo, fosse desenvolvida a interação espontânea, em situações funcionais e naturais de vida (WALTER, 2000).

Nas fases 1, 2, 3a, e 3b foram realizadas as sessóes de linha de base. Como na fase 3b o participante aluno entregava figuras aleatórias para a professora, sem função comunicativa, dessa forma ele não atingiu o critério estabelecido de acima de 70\%. Com isso a intervenção iniciou-se na fase $3 \mathrm{~b}$, onde foram inseridas ajudas para realização das atividades.

Fase 1 - Linha de base: para realização dessa fase, a pesquisadora optou em utilizar figuras de acordo com o cotidiano do participante aluno. Conforme realizava o pedido daquilo que desejava, entregando a figura para a professora, recebia o desejo. $\mathrm{O}$ aluno obteve êxito na linha de base de $100 \%$, não necessitando realizar a intervenção.

Fase 2 - Linha de base: nessa fase o aluno deveria aumentar a sua espontaneidade. Deveria chamar a professora através de gestos ou sons e depois entregava a figura. Portanto, a professora afastou-se do aluno e da prancha de comunicação e aguardou ser chamada caso o aluno quisesse realizar algum pedido e, quando esta se aproximasse de sua cadeira, deveria realizar a troca entregando a figura. $\mathrm{O}$ aluno não demonstrou dificuldades, chamou a professora através de sons com a boca, de gestos movimentando a cabeça e o olhar. Nessa fase o aluno também obteve êxito na linha de base de 100\%, não necessitando realizar a intervenção. 49

Fase $3 \mathrm{a}$ - Linha de base: o aluno foi orientado a fazer uma escolha entre as figuras dispostas em sua prancha e realizar a troca comunicativa. Nessa fase o aluno também obteve êxito na linha de base de $100 \%$, não necessitando realizar a intervenção. 
Fase $3 b$ - Linha de base e intervenção: as figuras diminuiriam de tamanho e que foram acrescentadas novas opções na prancha de comunicação alternativa. Com a diminuição das figuras, o aluno apresentou dificuldades, ocasionando um número maior de sessóes para essa fase. $\mathrm{O}$ aluno não obteve êxito na linha de base, sua pontuação foi $0 \%$, necessitando iniciar a intervenção com a inserção de ajudas.

As ajudas oferecidas foram auxílio físico e auxílio verbal sobre as figuras que estavam distribuídas na prancha, facilitando o entendimento do aluno. $\mathrm{Na}$ intervenção na fase $3 \mathrm{~b}$, com o auxílio maior da pesquisadora e da professora (auxílio físico e verbal), o aluno obteve independência e atingiu pontuaçóes acima de $70 \%$, permitindo assim iniciar a fase 4 .

Fase 4 - Intervenção: $\mathrm{O}$ aluno não sentiu dificuldades nessa fase, observou-se que o seu desempenho motor também melhorou. Passou a ter mais facilidade para pegar a figura, apontar ou olhar. $\mathrm{O}$ aluno foi orientado oralmente como deveria realizar a troca. $\mathrm{O}$ participante deveria utilizar as figuras com "eu quero" ou "eu estou" para formar frases simples, e desta forma, solicitar o que desejava. Sua pontuação foi acima de 70\%, cumprindo o critério para que pudesse realizar a fase 5.

Fase 5 - Intervenção: o procedimento foi o mesmo da fase 4, mas com a inserção de novas figuras e conceitos, como a discriminação de figuras que envolvem sentimentos e cores. Nas cinco sessóes o aluno necessitou dica demonstrativa e auxilio verbal, atingindo assim 92,5 $\%$ de desempenho.

Finalizadas as intervençóes, a pesquisadora realizou a avaliação da continuidade das fases do PECS-Adaptado, com uma tentativa de cada fase, para observar se as aprendizagens ensinadas foram mantidas. O aluno obteve $100 \%$ das respostas em cada fase do follow up.

A figura 2 mostra o desempenho do aluno nas sessões de linha de base, intervenção e follow up (avaliação de continuidade das fases).

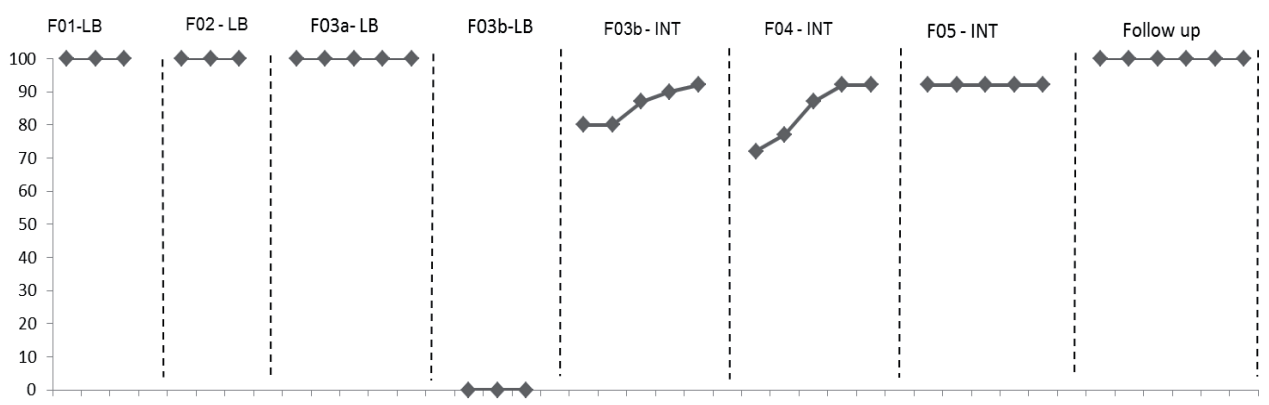

LEGENDA:

F01-LB : FASE 1 - LINHA DE BASE

F02-LB: FASE 2 - LINHA DE BASE
F03a-LB: FASE 3a- LINHA DE BASE F03b-LB: FASE 3b - LINHA DE BASE F03b-INT: FASE 3b - INTERVENÇĀO
F04 -INT: FASE 4 INTERVENÇĀO F05-INT: FASE 5 INTERVENÇĀO

Follow up: Avaliaçáo de continuidade das fases do PECS-Adaptado

Figura 2 - Porcentagens de acertos e erros do aluno com Paralisia Cerebral nas fases de linha de base, intervenção e follow up do PECS - Adaptado (WALTER, 2000).

Fonte: elaboração própria.

Com base nos dados apresentados na figura 2, pode-se dizer que o aluno apresentou desenvolvimento satisfatório e atingiu o objetivo dos procedimentos de ensino, começando a se comunicar por meio de figuras. 
A partir da introdução da intervenção na fase 3 b (figura 2), pode-se constatar que o mesmo apresentou mais facilidade para atender as solicitaçôes, além de melhorar seu perfil comunicativo. Também melhorou o seu desenvolvimento motor ao mexer o braço para pegar as figuras que iria se comunicar (TABITH, 1989; ROTTA, 2002).

Comparando os dados de intervenção com a fase de linha de base, nota-se que o aluno apresentou melhora significativa. Esses resultados vão ao encontro daqueles obtidos por Walter (2006), Walter (2000), Piza (2002), Almeida, Piza e Lamônica (2005) e Moreschi (2012).

A adaptação do PECS parece gerar os mesmos resultados positivos que o PECS original, ou seja, ambas as modalidades parecem ser efetivas no ensino de linguagem, e não só para indivíduos com autismo, uma vez que quatro crianças com paralisia cerebral (PIZA, 2002; ALMEIDA; PIZA; LAMÔNICA, 2005), também se beneficiaram do método (MIZAEL; AIELLO, 2013).

A disponibilidade e o empenho da professora foi muito importante para o andamento da pesquisa. Conforme os meses de coleta de dados aumentou a colaboração entre a pesquisadora e a professora, o que facilitou o andamento e estruturação da pesquisa.

No decorrer das visitas nas instituiçóes para a coleta dos dados, percebeu-se que a professora aperfeiçoou o seu conhecimento, segundo sua fala: "antes eu não tinha ideia do que se tratava este método, agora já estou tendo mais facilidade, estou mais disposta a ajudar e estou contente pelo aluno estar empenhado em todas as atividades aplicadas das fases do PECS." (sic).

Deliberato $(2009,2010)$ advertiu que o recurso pode facilitar as trocas comunicativas e a inserção do aluno com deficiência nas tarefas pedagógicas, desde que o professor tenha domínio das condiçóes específicas e externas do aluno com deficiência e as atividades estejam organizadas no contexto de um programa de intervenção.

Além de se sentir habilitada para auxiliar o aluno na escola, alegou que a área de comunicação alternativa é muito importante e falta envolvimento das pessoas nessa área: "Comunicação Alternativa é uma área muito ampla, você como pesquisadora está na área certa. Pode observar que tem muitas ocorrências, você precisa parar. Exige muito do profissional." (sic)

Após o treinamento das fases do PECS - Adaptado em sala de aula, os pais foram convidados para comparecer a escola. A mãe compareceu para a entrevista. Ela foi auxiliada pela professora e a pesquisadora sobre o uso da prancha de comunicação alternativa, de como ela deveria utilizar essa prancha em casa.

A mãe do participante achou a comunicação alternativa ótima e funcional, podendo auxiliar em alguns momentos: "Ele gostou muito. Ele praticamente me obrigou a utilizar em casa (risos)" (sic).

A mãe disse que vai começar a utilizar mais a comunicação alternativa em casa com o seu filho: "em casa eu que vou ensinar meu filho, ele só me chama em casa, as vezes eu falo que náo aguento mais, falo pro pai dele ver o que ele quer (risos). A escola também vai ensinar." (sic).

No decorrer do estudo observou-se que a família, especificamente a mãe do aluno, aprendeu junto com a professora e a pesquisadora a forma de ensinar o seu filho. Desta forma, 
demonstrou estar habilitada para auxiliar o seu filho na utilização da prancha de comunicação alternativa no ambiente domiciliar.

Deliberato e Sameshima (2007) demonstraram que os recursos e procedimentos da área de comunicação alternativa vêm favorecendo não só a ampliação das habilidades comunicativas, mas vem contribuindo com a aquisição e desenvolvimento da linguagem e aprendizagem escolar do aluno com deficiência.

O participante apresentava alterações nas habilidades de expressão, mas conseguiu manifestar seus desejos por meio de olhares, gestos, sons e pelas figuras. Diante dessas alteraçôes encontradas, verificou-se que a alternativa implementada para que o participante pudesse se expressar e suprir suas necessidades consistiu-se na associação dos sistemas PCS com o programa PECS-Adaptado.

Algumas adaptaçóes foram realizadas para que a comunicação alternativa do participante se tornasse efetiva. Inicialmente a pesquisadora havia disponibilizado uma prancha de papelão para que o aluno colocasse a figura desejada, após observar que seria mais fácil algo que ficasse próximo a ele e não sofresse modificaçóes, a pesquisadora juntamente com a professora e a Terapeuta Ocupacional resolveram adaptar sua tábua, encapando-a com papel contact e duas tiras de fita velcro; assim a tábua iria se fixar em sua cadeira, facilitando a colocação da figura.

Na fase 2, do PECS-Adaptado segundo Walter (2000), o participante deveria chamar a atenção da professora, através de um sino, para efetuar a troca comunicativa, como ele sentiu dificuldade para realizar a pressão do sino, foi adaptado pela pesquisadora para utilizar gestos ou sons, já que este realizava sons quando queria solicitar algo.

A partir da fase 4, a coleta de dados foi mais rápida, visto que as figuras aumentaram, houve um auxilio maior da professora e pesquisa e o aluno já estava familiarizado com as figuras, apesar da introdução de novas.

Além do que já foi exposto, cabe ressaltar que esta pesquisa apresentou algumas características específicas, por se tratar de um trabalho de associação entre dois sistemas alternativos, como uma única finalidade: promover a independência da comunicação do paralitico cerebral que inicialmente apresentava vocabulário pobre, com poucas interaçóes comunicativas (PIZA, 2003).

\section{Conclusóes}

A pesquisa foi signiticativa, a introdução do sistema PECS-Adaptado trouxe sucesso e melhora para a comunicação do aluno, como também melhorou o entendimento com seus interlocutores. Observou-se também a importância em desenvolver programas de comunicação alternativa com alunos que não apresentam a fala oral. Assim a comunicação alternativa surge como uma forma de suprir a ausência da fala oral por meio de outras formas de comunicação, como gestos, símbolos, expressóes, além de prover materiais baixa e alta tecnologia.

A parceria realizada entre a pesquisadora, a professora, a família e a escola foram fundamentais para o andamento da pesquisa. É necessário sempre haver essa parceria entre os 
profissionais da educação e a família para que o processo de implementação da Comunicação Alternativa ocorra de maneira eficiente.

De acordo com pesquisas e relatos apresentados neste estudo, pode-se observar que faltam estudos que envolvam aluno com paralisia cerebral, visto que a maioria dos artigos são publicados envolvendo alunos autistas, por isso o interesse em estudar com essa população.

O estudo foi significativo, pelo amplo empenho ao confeccionar as figuras, a prancha, as atividades, pelas visitas para coleta de dados, como também pela grande importância que essa área exige. Espera-se que traga contribuiçóes para a área da Educação Especial e que novas pesquisas sejam desenvolvidas.

\section{REFERÊNCIAS}

ALMEIDA, M. A.; PIZA, M. H. M.; LAMÔNICA, D. A. C. Adaptation of the picture exchange communication system in a school context (original title: Adaptaçôes do sistema de comunicação por troca de figuras no contexto escolar). Pró-Fono Revista de Atualização Científica, Barueri , v. 17, n. 2, p. 233-240, 2005.

AMERICAN SPEECH-LANGUAGE-HEARING ASSOCIATION - ASHA. Oxfordshire, 1991. Disponível em: <http://www.asha.org.> Acesso em: 01 out. 2016.

BADAWI, N. et al. What constitutes cererbral palsy? Developmental Medicine and Child Neurology, v. 40, n. 8, p. 520-527, 1998.

BONDY, A.; FROST, L. The Picture Exchange Communication System. Behavior Modification, v.25, n.5, p.725-744, 2001.

BRASIL. Saberes e práticas da inclusão: desenvolvendo competências para o atendimento às necessidades educacionais de alunos com deficiência física/neuro-motora. Coordenção geral SEESP/ $M E C$, Secretaria de Educação Especial, Brasília, DF, 2006, n. 2, 2006. p.36.

CARNEVALE, L. B. et al. Comunicação Alternativa no contexto educacional: conhecimento de professores, Rev. bras. educ. espec. , Marília, vol.19, n. 2, p. 243-256, 2013.

CHUN, R.Y.S.; MOREIRA, E. C. Comunicação Suplementar e/ou alternativa - ampliando possibilidades de indivíduos sem fala funcional. In: LACERDA, C.B.F.; PANHOCA, I. (Org.). Tempo de Fonoaudiologia. Taubaté: Cabral, 1997. p.97-113.

DELIBERATO, D.; MANZINI, E.; GUARDA, N. S. A implementação de recursos suplementares de comunicação: participação da família na descrição de comportamentos comunicativos dos filhos. Revista Brasileira de Educação Especial, Marília, v.10, n.2, p. 217-240, 2004.

DELIBERATO, D.; SAMESHIMA, F.S. Habilidades comunicativas utilizadas por um grupo de alunos não falantes durante atividade de jogo. In: NUNES, L.R.O.P.; PELOSI,M.B.; GOMES, M.R. (Org.) Um retrato da comunicaçâo alternativa no Brasil: relatos de pesquisas e experiências. Rio de Janeiro: 4 Pontos estúdio gráfico e papéis, v. 1, 2007. p. 118-122.

DELIBERATO, D. Comunicação alternativa na escola: habilidades comunicativas e o ensino da leitura e escrita. In: DELIBERATO, D.; GONÇALVES, M. J.; MACEDO, E.C. (Org). Comunicação alternativa: teoria, prática, tecnologias e pesquisa. São Paulo: Memnon Edições Científicas, 2009. p.235-243. 
DELIBERATO, D. Caracterização das habilidades expressivas de um aluno usuário de comunicação alternativa durante intervenção fonoaudiológica. 2010. 178 f. Tese (Livre-Docência) - Faculdade de Filosofia e Ciências, Universidade Estadual Paulista, Marília, 2010.

DUTRA, M. I.; FAGUNDES,S.L.; SCHIMER, C. R. Comunicação para todos - em busca da inclusão social e escolar In: NUNES, L.R.O.P.; PELOSI, M.B.; GOMES, M.R. (Org.) Um retrato da comunicação alternativa no Brasil: Relatos de pesquisas e experiências. Rio de Janeiro: Pontos estúdio gráfico e papéis, 2007. v.2. p.130-135.

GAST, D. L. Single subject research methodology in behavioral sciences. New York: Routledge, 2010.

GAST, D. L; LEFORD, J. Single case research methodology. 2.ed. London: Routledge, 2014.

JOHNSON, R. M. Manual do usuário Boardmaker. Comunicação e Facilitação. Porto Alegre: Clik Recursos Tecnológicos para Educação, 2005. Disponível em: < http://www.clik.com.br/> Acesso em: 01 out. 2016.

LEBLANC, J.M. El Curriculum Funcional em la Educación de la Persona com Retardo Mental. Simpósio Internacional COANIL, Chile: Santiago, 1991.

MANZINI, M. G. Efeito de um programa de comunicação alternativa para a

capacitação de mães de crianças com paralisia cerebral não verbal. 2013. 120f. Dissertação de Mestrado Centro de Educação e Ciências Humanas. Universidade Federal de São Carlos, São Carlos, 2013.

MILLER, G. Paralisias cerebrais: uma visão geral. In: MILLER, G.; CLARK, G. D. (Org.). Paralisia cerebral: causas, conseqüências e conduta. Barueri: Manole, 2002. p. 1-39.

MIRANDA, C.L.; GOMES, D.C.I. Contribuiçóes da comunicação alternativa de baixa tecnologia sem comunicação oral: relato de caso. Revista CEFAC, São Paulo, v.6, n.3, p. 247-252, 2004.

MIZAEL, T. M.; AIELLO, A. L. R. Revisão de Estudos Sobre o Picture Exchange Communication System (PECS) Para o Ensino de Linguagem a Indivíduos com Autismo e Outras Dificuldades de Fala. Rev. Bras. Ed. Esp., Marília, v. 19, n. 4, p. 623-636, 2013.

MORESCHI, L.C. Perfil comunicativo de usuário de Sistemas de Comunicação Alternativa na Interação com Diferentes Parceiros. 2012. 182 f. Tese de Doutorado em Educação Especial - Departamento de Psicologia. Universidade Federal de São Carlos, São Carlos. 2012.

NUNES, L. R. Linguagem e Comunicação Alternativa: Uma introdução. In: NUNES, L.R. (Org.). Favorecendo o desenvolvimento da comunicação em crianças e jovens com necessidade educacionais especiais. Rio de Janeiro: Dunya, 2003. p. 1-13.

NUNES, D.R.P. Introdução. In: MANZINI, E.J. et al. (Org.). Linguagem e comunicação alternativa. Londrina: ABPEE, 2009. p.1-8.

NUNES, D. R. P.; AZEVEDO, M. O.; FREIRE, J. G. Comunicação Alternativa em sala de aula: relatos de uma professora de alunos com autismo. In: NUNES, L.R.O.; PELOSI, M. B., WALTER, C.C.F. (Org.). Compartilhando experiências: ampliando a comunicação alternativa. Marília: ABPEE, 2011. p. 194.

OMS. Organização Mundial da Saúde. Classificação Internacional de Funcionalidade, Incapacidade e Saúde - CIF. Sáo Paulo: Editora da Universidade de São Paulo - EDUSP, 2008.

PELOSI, M.B. Formação em serviço de professores de salas multifuncionais para o desenvolvimento da comunicação alternativa com os alunos com necessidades educacionais especiais. Relatório de Pesquisa. FAPERJ E - 26/110.039/2010. 
PIZA, M.H.M. O uso dos métodos alternativos PECS-Adaptado e PCS para aumentar habilidades comunicativas em paralíticos cerebrais, não verbais. 2002. 102f. Dissertação (Mestrado em Educação Especial) - Departamento de Psicologia, Universidade Federal de São Carlos, Sáo Carlos, 2002.

ROTTA, N. T. Paralisia cerebral, novas perspectivas terapêuticas. Jornal Pediatria, Rio de Janeiro, v. 78, Supl.1, p.48-54, 2002.

SAMESHIMA, F. S.; DELIBERATO, D. Habilidades expressivas de um grupo de alunos com paralisia cerebral na atividade de jogo. Revista sociedade brasileira de fonoaudiologia, São Paulo, v. 14, n.2, p.219224, 2009.

SILVA, R. L. M. et al. Efeitos da comunicação alternativa na interação professor-aluno com paralisia cerebral não-falante. Revista brasileira de educação especial, Marília, v. 19, n.1, p.25-42, 2013.

TETZCHNER, V. S. Suporte ao desenvolvimento da comunicação suplementar e alternativa. In: DELIBERATO, D.; GONÇALVES, M. J.; MACEDO, E. C. (Org.). Comunicação alternativa: teoria, prática, tecnologias e pesquisa.São Paulo: Memnon Ediçóes Científicas, 2009. p. 14-27.

TABITH, A. Foniatria: disfonias, fissuras labiopalatais, paralisia cerebral. Cortez Editora, São Paulo, caderno 5, p. 51-117, 1989.

WALTER, C.C F. Os efeitos da adaptação do PECS associada ao curriculum funcional natural em pessoas com autismo infantil. 2000. 89 f. Dissertaçáa (Mestrado em Educaçáa Especial) - Departamento de Psicologia, Universidade Federal de São Carlos, São Carlos, 2000.

WALTER, C.C. F. Avaliação de um Programa de Comunicação Alternativa e Ampliada para Mães de Adolescentes com Autismo. 2006. 107 f. Tese (Doutorado em Educação Especial) - Departamento de Psicologia, Universidade Federal de São Carlos, São Carlos, 2006.

Recebido em: 16/03/2016

Reformulado em: 11/10/2016

Aprovado em: 20/10/2016 
EVARISTO, F.L. \& ALMEIDA, M.A. 